\title{
What Drives Entrepreneurial Orientation in BUMDes? Evidence from East Java Indonesia
}

\author{
Syafrial $^{1}$, Dwi Retnoningsih ${ }^{2}$, Moh. Shadiqur Rahman ${ }^{3}$, Hari Wahyu Wijayanto ${ }^{4}$ \\ \{syafrial.fp@ub.ac.id ${ }^{1}$,dwiretnoningsih@ub.ac.id², mohsodiqurrahman@gmail.com³ \\ hariwahyu.wijayanto@gmail.com ${ }^{4}$ \} \\ Department of Socio-economics, Faculty of Agriculture, Brawijaya University, Indonesia ${ }^{1,2}$ \\ Department of Tropical Agriculture and International Cooperation, National Pingtung \\ University of Science and Technology, Pingtung, Taiwan ${ }^{3,4}$
}

\begin{abstract}
This study aims to analyze the factors that influence entrepreneurial orientation BUMDes. Respondents of this research are the manager BUMDes in Blitar and Malang. The data analysis method used is a multivariate technique Structural Equation Model (SEM), based on the consideration that the SEM has the ability to combine the measurement model and the structural model of simultaneous when compared with other multivariate techniques. The structural model has shown that work discretion has a significant entrepreneur orientation. Management support is through Entrepreneur orientation, which will have a negative effect on entrepreneur orientation. However, reward/recognition has a significant effect on entrepreneur orientation. However, Resources have an insignificant effect on Entrepreneur Orientation, and KPI focus on entrepreneur orientation is significant and positive. However, negative and significant effects on entrepreneur orientation are also given by expectation. Localism found a significant and positive effect on entrepreneur orientation.
\end{abstract}

Keywords: BUMDes; Entrepreneurial Orientation; Structural Equation Modelling

\section{Introduction}

Entrepreneurial orientation is a phenomenon that reflects an organization's managerial capability used by a company or business entity to embark on a proactive and aggressive initiative to change the competitive arena into profit [1]. More specifically, according to [2] Entrepreneurship is a multi-dimensional concept, which has the important factors that need to be considered related to performance, such as one cultural factor Because culture influences the nature of life's decisions where the value system of cultural elements directly affect the behavior of individuals in the entrepreneurial Orientation [3].

Please note that the entrepreneurial organization needed a strategy to decide an action to be performed. The statement is in accordance with that expressed by [4]. Entrepreneurship is multi-dimensional concept, which has the important factors that need to be considered related to performance, such as one cultural factor. Because culture influences the nature of life's decisions where the value system of cultural elements directly affect the behavior of 
individuals in the entrepreneurial orientation, in terms of actions taken, resources committed, or precedents established," the policies and practices that serve as the foundation for entrepreneurial decisions and actions are referred to as entrepreneurial orientation. As a result, entrepreneurial orientation can be viewed as a process in the manufacture of entrepreneurial strategies used by decision-makers and key used to establish firm organizational goals, maintaining the vision, and create a competitive advantage of the company. So that entrepreneurial orientation is very important to improve the performance of a company.

Suppose we observe many companies based in urban areas while in rural, less consideration to set up a company. According to [5] development of rural areas is very important because the structure of the rural economy is in a state which does not compare favorably with the urban structure. So that the Government has made efforts to alleviate the deficiencies of the village, such as empowerment by increasing the budget for rural development from year to year in order to be able to reduce the number of villages were left behind, and some other programs such as the establishment of village-owned enterprises (BUMDes).

Related Research entrepreneurial orientation, one of which is done by Avlonitis and Salavou [1], with their entrepreneurial orientation, can improve the Small and Medium Enterprises (UKM) performance in Greece with innovative products. To enhance the entrepreneurial orientation of BUMDes, the study aims to analyze the factors that increase the entrepreneurship orientation BUMDes approach SEM Structural Equation Model.

\section{Measuring Entrepreneurship Orientation BUMDes}

Some questions were submitted to measure entrepreneurial orientation on each BUMDesa. Answers from respondents will be assessed by Likert scale 1-5 (for strongly disagree to strongly agree). Following questions that will be used to measure the entrepreneurial orientation BUMDes:

Table 1. Measuring Entrepreneurship Orientation

\begin{tabular}{cl}
\hline Indicators & \multicolumn{1}{c}{ Question } \\
\hline Innovativeness & $\begin{array}{l}\text { "is open to innovations." } \\
\text { "is creative." } \\
\text { "often implements new approaches to meet its responsibilities." }\end{array}$ \\
"rarely behaves hesitantly. (Reverse)" \\
"responds to [labor/training] market changes as they occur." \\
"often approaches external groups to initiate projects." \\
"also implements promising but risky projects." \\
"often gets involved, even if the outcome is initially uncertain." \\
"is especially careful in its course of action. (Reverse)."
\end{tabular}




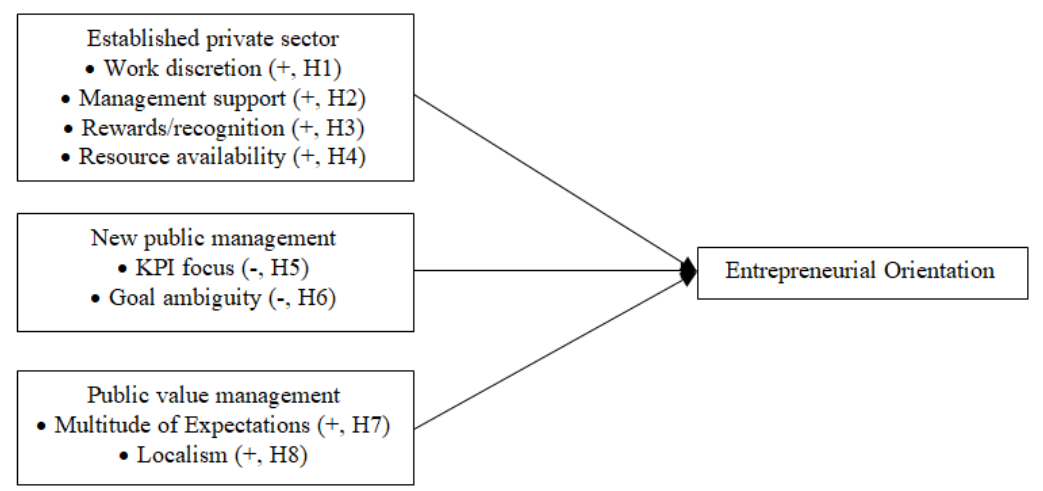

Fig. 1. Research Hypothesis

\section{Methodology}

\subsection{Research Data}

This study was conducted in two districts in East Java province, the district of Malang and Blitar. Electoral district location careful consideration that Blitar district is a district that quite a lot of actors who founded BUMDes, but a lot of that condition is not good. Malang also been due to many BUMDes established, but conditions are still evolving. The data used are primary data with data collection techniques were used that survey using a questionnaire instrument. The questionnaire comprised of open and closed questions. Questionnaires will be divided into three groups. The first is related questions BUMDES profile. Secondly, the question is about revenue or earnings, and the third question is about the condition of BUMDes performance. Finally, the questionnaire contains questions related to indicators of entrepreneurial orientation.

\subsection{Data Analysis}

The elements that impact entrepreneurial Orientation will be estimated using data analytic methods. BUMDes is Structural Equation Modeling (SEM). For structural equation modeling (SEM) analysis, the smallest sample size required was 100-150. The sample variable and sample size ratio of 1:10 is the minimal need for sample size based on estimations using the approach of greatest probability. [2]. This study has 21 sample variables and 252 effective samples, which exceeds the minimum sample size guidelines for SEM analysis. 
Table 2. Analysis of confirmatory factors.

\begin{tabular}{cccccc}
\hline Variable & Factor Loading & SMC & 1-SMC & CR & AVE \\
\hline Entrepreneur orientation (EO) & 0.760 & 0.578 & 0.422 & 0.835 & 0.522 \\
Work discretion (WD) & 0.802 & 0.643 & 0.357 & 0.804 & 0.578 \\
Management support (MS) & 0.858 & 0.736 & 0.264 & 0.785 & 0.556 \\
Reward/recognition (RW) & 0.821 & 0.674 & 0.326 & 0.723 & 0.573 \\
Resources (RC) & 0.840 & 0.706 & 0.294 & 0.811 & 0.590 \\
KPI focus (KPI) & 0.857 & 0.734 & 0.266 & 0.902 & 0.650 \\
Goal ambiguity (GA) & 0.908 & 0.824 & 0.176 & 0.797 & 0.587 \\
Expectation (EX) & 0.816 & 0.666 & 0.334 & 0.861 & 0.555 \\
Localism (LC) & 0.850 & 0.723 & 0.278 & 0.829 & 0.620 \\
\hline
\end{tabular}

\section{Result and Discussion}

\subsection{The analysis of reliability and validity}

According to this research, the dimensions' composite reliability (CR) values are 0.835 , $0.804,0.785,0.723,0.811,0.902,0.797,0.861,0.829$, with the greater the number, the better the internal consistency of variables. The average variance extract (AVE) indicates how much variation the latent variable captures when compared to other variables in the dimension. The greater the AVE score, the more latent trait common factor across dimensions the observed variables might respond. As shown in Table 2, the AVE values for the dimensions are 0.522, $0.578,0.556,0.573,0.590,0.650,0.587,0.555,0.620$, respectively. The CR and AVE have reached the standard and correspond to the recommendation by [6], The CR must be greater than 0.7, the AVE must be greater than 0.5, and the connection between consistency and convergent validity should be present in all dimensions. The remainder of the question values is more than 0.6. As a result, the model's six dimensions demonstrated strong convergent validity.

The discriminant validity of all dimensions is examined using AVE in this study. The square roots of AVE are greater than Pearson's correlation coefficients across all dimensions, indicating that discriminant validity exists. [7], as shown in Table 3.

Table 3. Discriminant validity

\begin{tabular}{cccccccccc}
\hline & EO & WD & MS & RW & RC & KPI & GA & EX & LC \\
\hline EO & 0.650 & & & & & & & & \\
WD & 0.261 & 0.760 & & & & & & & \\
MS & 0.166 & 0.216 & 0.746 & & & & & & \\
RW & 0.254 & 0.257 & 0.223 & 0.688 & & & & & \\
RC & 0.346 & 0.317 & 0.237 & 0.429 & 0.768 & & & & \\
KPI & 0.256 & 0.299 & 0.177 & 0.266 & 0.380 & 0.806 & & & \\
GA & 0.307 & 0.282 & 0.228 & 0.313 & 0.574 & 0.325 & 0.766 & & \\
EX & 0.242 & 0.274 & 0.176 & 0.259 & 0.439 & 0.290 & 0.408 & 0.745 & \\
LC & 0.303 & 0.296 & 0.224 & 0.368 & 0.596 & 0.353 & 0.467 & 0.414 & 0.787 \\
\hline
\end{tabular}

\subsection{Goodness of Fit}

The following indicators are used to check the goodness of fit in this study: $\chi 2$, the value of $\chi 2$, degree of freedom $(\chi 2 / \mathrm{df})$, goodness of fit index (GFI), adjusted goodness of fit index 
(AGFI), root mean square error of approximation (RMSEA). Because $\chi 2$ is easily influenced by the number of samples, a higher value of $\chi 2$ indicates that the model does not fit. Therefore, To check the quality of fit, use the value of $\chi 2$ and the degree of freedom as an indication [8]. When the number is less than 3, the model is said to have a superior goodness of fit. When the GFI and AGFI numbers are between 0 and 1,MacCallum and Hong [9] suggested When the GFI and AGFI values are more than 0.8 , the model exhibits sufficient goodness of fit. Doğan and Özdamar [10] recommended that When the RMSEA is between 0.05 and 0.09, the model has a decent fit. Chi-Square/df 3.545, GFI 0.857, AGFI 0.871, and RMSEA 0.089 were used in this study's model.

\begin{tabular}{ccc}
\multicolumn{3}{c}{ Table 4. Goodness of Fit } \\
\hline GOF & Criteria & Value \\
\hline Chi-Square/df & $<5.00$ & 3.545 \\
GFI & $>0.800$ & 0.857 \\
AGFI & $>0.800$ & 0.871 \\
RMSEA & $<0.090$ & 0.089 \\
\hline
\end{tabular}

\subsection{Hypothesis Results}

The structural model has revealed, as shown in Table 5, that work discretion has a significant entrepreneur orientation. Management support is through entrepreneur orientation, which will have a negative effect on entrepreneur orientation. However, reward/recognition has a significant effect on entrepreneur orientation. Likewise, resources have an insignificant effect on entrepreneurial orientation. and KPI focus on entrepreneur orientation is significant and positive. however, negative and significant effect on entrepreneur orientation also given by ambiguity. Expectation and localism found a significant and positive effect on entrepreneur orientation. Conclusions of hypotheses Table 5 displays the results of the hypothesis verification for all dimensions. The focus of health resources on KPIs is insignificant; management support and resources on entrepreneur orientation are insignificantly positive relation ( $\mathrm{H} 2, \mathrm{H} 4$, and $\mathrm{H} 5$ were not supported). The finding shows that work discretion, reward/recognition, goal ambiguity, expectation and localism are significantly positively related to Entrepreneur Orientation. These results validate H1, H3, H6, H7 and H8.

The findings of our first sequence of hypotheses show the importance and the interpretation of the phenomena being investigated by deliberately moving ideas from the private to the public sector. As regards business entrepreneurship, our research contributes to a different context, particularly in middle management, by validating the organizational history. Explicit calls have been made for the appraisal of business entrepreneurship abroad [11]. We provide initial proof that management support, availability of resources also affect public sector agency level EO positively, along with private sector research $[12,13]$.

This management support, the work direction, and the availability of resources also impacts public sector EO at the departmental level. These histories have significant, since their statistics come from the same institution missing the other histories covered by the report. These histories have beneficial results. This underlies the finding by [14] of the value of interpretation instead of merely the apparent structure or organizational architecture. However, when taking additional backgrounds into account, the influence of these antecedents is minimal and slightly diminishing. The findings however lead us to speculate on sectoral precedents. It is not shocking that a positive community - which provides assistance in tough circumstances rather than blame - pays off with respect to EO, which therefore regulates money and leeway. In other words, our outcomes will promote discussions on the general 
human tenness of current Eos. Our second set of hypotheses counteract undifferentiated NPM requirements. Students and analysts concluded that a heavy reliance on simple, quantifiable targets would have a negative effect on the success of a public sector agency. We see no proof of such claims in relation to EO in our con-technology. As the commercial facets of the public manager's activities are just one side of his tasks, aside from handling routine jobs, our data can only be read in this specific area. The KPI focus has insignificant impact on the EO. This result is consistent with the finding made by Marginson [14], whose impact on creation and new concepts is not prevented by use of KPI.

The overall composition is generally consistent and thus can have a small difference. However, the interpretation based on the observed variances in the system seems to be more suitable: there is minimal explicative capacity in organizational antecedents. In line with Meynhardt and Diefenbach [15] findings, organizations are not the key source of conflicts between the FLA and their position. Our third set of hypotheses findings help PVM researchers. EO tends to be encouraged by constructive interest in the immediate local community. Managerial behavior and EO-enhancing, as predicted by Meynhardt and Diefenbach [15] is heavily motivated by a wide number of desires. In identifying and achieving the entrepreneurship opportunities of the public sector, the local needs and core stakeholders have a key role. This concerns H8's support: EO is positively influenced by localism, this is because of localism improve enterprises commitment and ability to fulfill local neighborhood requirements.

The key determinant of EO at departmental level is tenure at the rental position/ department level in our research. This style of tenure, along with many expectations and locality, tends to be the most successful. Such neighborhood engagement can help individuals obtain access to appropriate stakeholders and find market opportunities. The creation of the networks beyond the company and/or inside the department appears more pertinent than the rest of the organization. The organization's tenures do not impact EO substantially. Embeddedness and social networking have been highlighted as a significant feature of corporate entrepreneurial, but little longitudinal study has been conducted on the connections between tenure and $\mathrm{EO}$ in the private sector.

Table 5. Hypothesis result

\begin{tabular}{ccccccccc}
\hline \multicolumn{2}{c}{ Regression Path } & Hypothesis & $\begin{array}{c}\text { Path } \\
\text { Coefficient }\end{array}$ & SE & $\begin{array}{c}\text { t- } \\
\text { value }\end{array}$ & P-value & Conclusion \\
\cline { 1 - 6 } EO & $<---$ & WD & H1 & 0.453 & 0.121 & 3.744 & $0.000^{* * *}$ & Supported \\
EO & $<---$ & MS & H2 & -0.303 & 0.133 & -2.272 & $0.023^{* *}$ & Not Supported \\
EO & $<---$ & RW & H3 & 0.243 & 0.124 & 1.969 & $0.049 * *$ & Supported \\
EO & $<---$ & RC & H4 & 0.048 & 0.135 & 0.358 & 0.720 & Not Supported \\
EO & $<---$ & KPI & H5 & 0.093 & 0.103 & 0.904 & 0.366 & Not Supported \\
EO & $<---$ & GA & H6 & -0.389 & 0.163 & -2.386 & $0.017 * *$ & Supported \\
EO & $<---$ & EX & H7 & 0.247 & 0.080 & 3.083 & $0.002 * * *$ & Supported \\
EO & $<---$ & LC & H8 & 0.199 & 0.095 & 2.104 & $0.035^{* *}$ & Supported \\
\hline \multicolumn{7}{r}{ Note $* *$ and $* * *$ donates significant in $5 \%$ and $1 \%$ respectively } &
\end{tabular}

Note: $* *$ and $* * *$ donates significant in $5 \%$ and $1 \%$ respectively 


\section{Conclusion}

From the result of this research, we can conclude that work discretion has a significant on Entrepreneur Orientation. Management support is through Entrepreneur Orientation, which will have a negative effect on entrepreneur orientation. However, reward/recognition has a significant effect on entrepreneur orientation. However, Resources and KPI focus have an insignificant effect on entrepreneur orientation. However, negative and significant effects on entrepreneur orientation are also given by goal ambiguity. Expectation and localism found a significant and positive effect on Entrepreneur Orientation.

\section{Acknowledgement}

This research is supported by Doctoral Research Grant program of the Universitas Brawijaya under contract No. 2368/UN10.F04/PN/2020.

\section{References}

[1] Avlonitis, G.J.; Salavou, H.E. Entrepreneurial orientation of SMEs, product innovativeness, and performance. Journal of Business Research 2007, 60, 566-575.

[2] Jackson, D.L. Revisiting sample size and number of parameter estimates: Some support for the N: q hypothesis. Structural equation modeling 2003, 10, 128-141.

[3] Akpor-Robaro, M.O.M. The impact of socio-cultural environment on entrepreneurial emergence: A theoretical analysis of Nigerian society. European Journal of Business and management 2012, 4, 172-182.

[4] Mason, M.C.; Floreani, J.; Miani, S.; Beltrame, F.; Cappelletto, R. Understanding the impact of entrepreneurial orientation on SMEs' performance. The role of the financing structure. Procedia Economics and Finance 2015, 23, 1649-1661.

[5] I Wayan Lasmawan, L.; Ni Desak Made Sri Adnyawati, S.; I Dewa Ayu Made Budhyani, D.A.; I Nyoman Sila, S.; I Made Sundayana, S.; I Wayan Suwendra, S. Spectrum of Social Science Education: Reconstruction of Social Science Competencies Based on Vygotsky's Social Reconstruction Formula in Primary School. Medwell Journals, Journal of Engineering and Apllied 2019, 14, 4347-4355.

[6] Zahoor, H.; Chan, A.P.; Utama, W.P.; Gao, R.; Memon, S.A. Determinants of safety climate for building projects: SEM-based cross-validation study. Journal of construction engineering and management 2017, 143, 05017005.

[7] Fornell, C.; Larcker, D.F. Evaluating structural equation models with unobservable variables and measurement error. Journal of marketing research 1981, 18, 39-50.

[8] Cangur, S.; Ercan, I. Comparison of model fit indices used in structural equation modeling under multivariate normality. Journal of Modern Applied Statistical Methods 2015, 14, 14.

[9] MacCallum, R.C.; Hong, S. Power analysis in covariance structure modeling using GFI and AGFI. Multivariate Behavioral Research 1997, 32, 193-210. 
[10] Doğan, İ.; Özdamar, K. The effect of different data structures, sample sizes on model fit measures. Communications in Statistics-Simulation and Computation 2017, 46, $7525-7533$.

[11] Ojo, S. Ethnic enclaves to diaspora entrepreneurs: A critical appraisal of black British Africans' transnational entrepreneurship in London. Journal of African Business 2012, $13,145-156$.

[12] Hornsby, J.S.; Kuratko, D.F.; Shepherd, D.A.; Bott, J.P. Managers' corporate entrepreneurial actions: Examining perception and position. Journal of business venturing 2009, 24, 236-247.

[13] Hornsby, J.S.; Kuratko, D.F.; Zahra, S.A. Middle managers' perception of the internal environment for corporate entrepreneurship: assessing a measurement scale. Journal of business Venturing 2002, 17, 253-273.

[14] Marginson, S. Towards a politics of the enterprise university [Paper in: Scholars and Entrepreneurs: the Universities in Crisis, Cooper, Simon, Hinkson, John and Sharp, Geoff (eds.).]. Arena Journal 2002, 109-136.

[15] Meynhardt, T.; Diefenbach, F.E. What drives entrepreneurial orientation in the public sector? Evidence from Germany's federal labor agency. Journal of Public Administration Research and Theory 2012, 22, 761-792. 